\title{
Can developed economies combat dangerous anthropogenic climate change without near-term reductions from developing economies?
}

\section{A letter}

\author{
Stephanie T. Waldhoff • Allen A. Fawcett
}

Received: 12 April 2011 / Accepted: 2 June 2011 / Published online: 6 July 2011

(C) The Author(s) 2011. This article is published with open access at Springerlink.com

\begin{abstract}
Developing economy greenhouse gas emissions are growing rapidly relative to developed economy emissions (Boden et al. 2010) and developing economies as a group have greater emissions than developed economies. These developments are expected to continue (U.S. Energy Information Administration 2010), which has led some to question the effectiveness of emissions mitigation in developed economies without a commitment to extensive mitigation action from developing economies. One often heard argument against proposed U.S. legislation to limit carbon emissions to mitigate climate change is that, without participation from large developing economies like China and India, stabilizing temperature at 2 degrees Celsius above preindustrial (United Nations 2009), or even reducing global emissions levels, would be impossible (Driessen 2009; RPC Energy Facts 2009) or prohibitively expensive (Clarke et al. 2009). Here we show that significantly delayed action by rapidly developing countries is not a reason to forgo mitigation efforts in developed economies. This letter examines the effect of a scenario with no explicit international climate policy and two policy scenarios, full global action and a developing economy delay, on the probability of exceeding various global average temperature changes by 2100 . This letter demonstrates that even when developing economies delay any mitigation efforts until 2050 the effect of action by developed economies will appreciably reduce the probability of more extreme levels of temperature change. This paper concludes that early carbon mitigation efforts by developed economies will considerably affect the distribution over future climate change, whether or not developing countries begin mitigation efforts in the near term.
\end{abstract}

Both authors are economists in EPA's Climate Change Division. The views expressed in this paper are those of the authors and do not necessarily represent those of the U.S. Environmental Protection Agency.

S. T. Waldhoff $(\varangle)$. A. A. Fawcett

U.S. Environmental Protection Agency, Washington, DC, USA

e-mail: waldhoff.stephanie@epa.gov 


\section{Probability, temperature, mitigation, scenarios}

Developing economy greenhouse gas emissions are growing rapidly relative to developed economy emissions. China has overtaken the United States as the largest emitter of fossil fuel $\mathrm{CO}_{2}$ to the atmosphere, and developing economies as a group have greater emissions than developed economies (Boden et al. 2010). These developments are expected to continue (U.S. Energy Information Administration 2010), which has led some to question the effectiveness of emissions mitigations in developed economies such as the United States. One often heard argument against proposed U.S. legislation to limit carbon emissions to mitigate climate change is that, without participation from large developing economies like China and India, stabilizing temperature, or even reducing global emissions levels, would be impossible (Driessen 2009; RPC Energy Facts 2009) or prohibitively expensive. While it is true that a delay in developing economy action to reduce $\mathrm{CO}_{2}$ emissions would greatly increase the cost of stabilizing greenhouse gas concentrations at any given level, ${ }^{1}$ the gains from developed country mitigation-even when developing economy action is greatly diminished or delayed-are still large. In this paper we estimate the potential effectiveness of developed country leadership in reducing the likelihood of observed global mean temperature exceeding $2^{\circ} \mathrm{C},{ }^{2}$ even if developing economies delay emissions mitigation efforts until after mid-century. We find that the effect of early mitigation action on the part of developed economies significantly reduces the probability of large temperature changes in 2100 while increasing the probability of lower temperature changes, as compared to a no policy scenario.

This paper examines three scenarios: a scenario with no concerted action to mitigate emissions ("No Policy"), a scenario intended to represent full and immediate global participation in limiting greenhouse gas emissions ("Full Participation"), and a scenario where all developing economies take no action to mitigate emissions until 2050 ("Developing Economy Delay"). ${ }^{3}$

The no policy case uses the emissions pathways from the MiniCAM model's EMF 22 no policy scenario (Calvin et al. 2009). The full participation scenario is based on the commitments made at the July 2009, Major Economies Forum where, "the G8 leaders agreed to reduce their emissions $80 \%$ or more by 2050 as its share of a global goal to lower emissions $50 \%$ by 2050 , acknowledging the broad scientific view that warming should be limited to no more than two degrees Celsius (White House 2009)," and the caps on emissions from the recently debated Senate American Power

\footnotetext{
${ }^{1}$ In the Energy Modeling Forum 22 exercise, Clarke et al. (2009) showed that 12 out of 14 participating models could not achieve stabilization of $\mathrm{CO}_{2} \mathrm{e}$ concentrations of $450 \mathrm{ppm}$ by the end of the century when developing countries delayed action until 2030 or later, and in all stabilization scenarios costs were higher in the delayed participation cases.

${ }^{2}$ This paper focuses on the probability of a change in observed global mean temperature as a proxy for the impacts likely to be caused by climate change under specific scenarios. Another part of the uncertainty stems from the possibility of extreme damages at even moderate levels of temperature change and the increasing likelihood of catastrophic damages at higher levels of temperature change. The authors acknowledge the uncertainty over translating changes in temperatures to physical impacts and economic damages. For examples of the catastrophic damages discussion in the current literature, see Weitzman (2010).

${ }^{3}$ The scenarios presented in this letter are from EPA's 2010 analysis of the American Power Act. For a complete description of the scenarios, see (U.S. Environmental Protection Agency 2010).
} 
Fig. 1 Annual greenhouse gas emissions under alternate scenarios

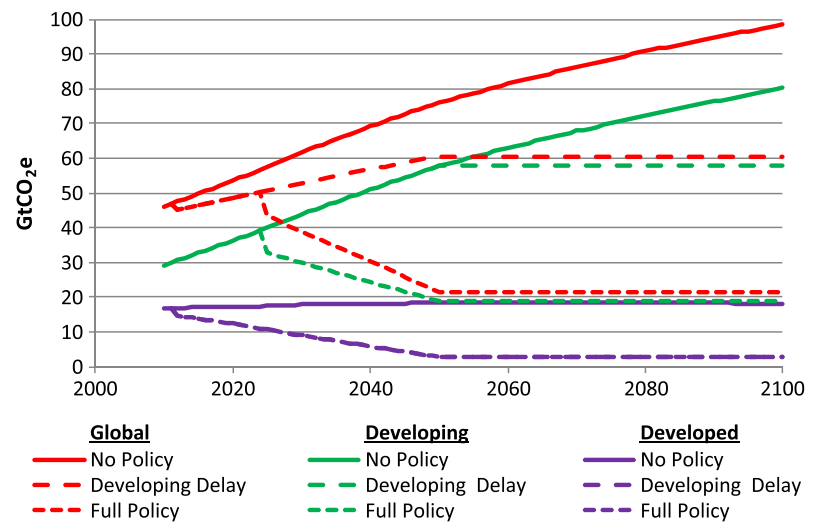

Act (APA), which has a 2050 cap on US emissions that is $83 \%$ below 2005 levels in 2050. Under these assumptions the US, as well as other developed countries, all reduce emissions to $83 \%$ below 2005 levels by 2050. Developing countries adopt a policy beginning in 2025 that caps emissions at 2015 levels, and linearly reduce emissions to $26 \%$ below 2005 levels by 2050 in order to meet the $50 \%$ global reduction target agreed upon at the Major Economies Forum. In the developing economy delay scenario, developed economies adopt the same targets as in the full participation case; however, developing economies do not adopt any climate policies until 2050, after which their emissions are held constant at 2050 no policy levels. These stylized scenarios demonstrate alternate levels of emissions that could occur under many potential futures. Figure 1 depicts the annual greenhouse gas emissions in each region under these three scenarios, and Table 1 shows the 20102100 cumulative emissions and cumulative abatement demand by region in each scenario.

Figure 2 shows the approximate probability of observed global mean temperature changes in 2100, relative to pre-industrial, under no policy, developing economy delay, and full participation scenarios. ${ }^{4,5}$ We developed these figures using a simple climate model, the Model for the Assessment of Greenhouse-gas Induced Climate Change (MAGICC) 5.3, (Wigley 2011) and the distribution over climate sensitivity reported by Roe and Baker (2007) truncated $\left(\right.$ at $\left.10^{\circ} \mathrm{C}\right)$ as implemented by the US Government in the 2010 Social Cost of Carbon exercise (U.S. Government Interagency Working Group on Social Cost of Carbon 2010). These figures demonstrate the resulting approximate probability of specific ranges of observed global mean temperature change.

For instance, under the no policy scenario, the probability of attaining the G8 goal of not exceeding a temperature change in 2100 of $2{ }^{\circ} \mathrm{C}$ is approximately $1 \%$. Under the full global participation scenario this probability increases to $75 \%$. Under the delayed participation scenario this probability is $11 \%$, an order of magnitude change

\footnotetext{
${ }^{4}$ Observed temperature change is that resulting from the concentration levels in a specific year.

${ }^{5}$ These are similar in style to the MIT Joint Program on the Science and Policy of Global Change temperature "roulette wheels" developed in 2009 that depict "policy" and "no policy" gambles over temperature change (Webster et al. 2003). See also http://globalchange.mit.edu/resources/gamble/.
} 
Table 1 2010-2100 Cumulative greenhouse gas emissions and abatement $\left(\mathrm{GtCO}_{2} \mathrm{e}\right)$

\begin{tabular}{lcllllll}
\hline & \multicolumn{3}{c}{ 2010-2100 cumulative GHG emissions } & & \multicolumn{3}{l}{ 2010-2100 cumulative GHG abatement } \\
\cline { 2 - 4 } & Developed & Developing & Global & & Developed & Developing & Global \\
\hline No policy & 1,646 & 5,284 & 6,930 & & - & - & - \\
Developing delay & 516 & 4,679 & 5,195 & & 1,130 & 606 & 1,736 \\
Full participation & 516 & 2,120 & 2,635 & & 1,130 & 3,165 & 4,295 \\
\hline
\end{tabular}

from the no policy. Additionally, the probability of remaining between $2^{\circ}$ and $3^{\circ}$ above pre-industrial temperatures increases from $29 \%$ in the no policy scenario to $47 \%$ in the delayed participation scenario. The delay scenario has a near doubling of the probability of remaining below $3^{\circ}$ compared to the no policy scenario.

A primary advantage of the probabilistic presentation of observed temperature changes in Fig. 2 is that, in addition to clearly depicting the chances of meeting the two degree Celsius target, the risks of observing more extreme temperature changes are also clear. Much recent discussion around climate policy has involved reducing the risk of catastrophic or severe climate impacts. Temperature can serve as a useful proxy for these impacts. The probability of the global mean temperature increase above preindustrial being $4{ }^{\circ} \mathrm{C}$ or greater is about $32 \%$ in the no policy case. This probability is reduced to essentially zero in the full participation case and even in the case of delayed developing economy action the probability of exceeding $4^{\circ} \mathrm{C}$ is cut in half to approximately $15 \%$. The most extreme outcome, an increase of $6^{\circ}$ to $8^{\circ} \mathrm{C}$, has a $4.7 \%$ chance of occurring in the no policy scenario, while the probability under the delayed developing economy action scenario is one eighth as large, at $0.6 \%$.

In all three scenarios, the temperature in 2100 is not stabilized and the observed change in global mean temperature in 2100 is not equal to the equilibrium change in global mean temperature. There are two reasons for this. First, equilibrium temperature change (Fig. 3) cannot be achieved until $\mathrm{CO}_{2}$ e concentrations, not just emissions, are constant $\left(\mathrm{CO}_{2} \mathrm{e}\right.$ concentrations in each scenario under different climate sensitivities are shown in Fig. 4). While the G8 international goals stabilize global greenhouse gas emissions at $50 \%$ below 2005 levels, $\mathrm{CO}_{2}$ e concentrations, and therefore temperature, are not stabilized. Second, even if concentrations were stabilized, the inertia in ocean temperatures causes the equilibrium global mean surface temperature change to lag behind the observed global mean surface temperature
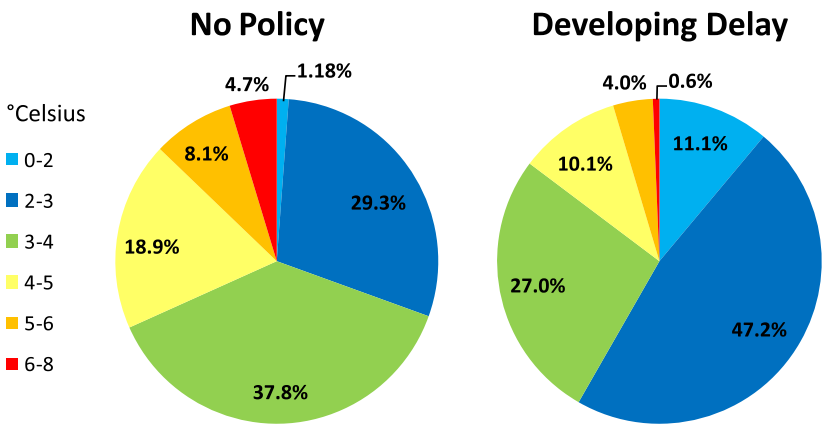

\section{Full Participation}

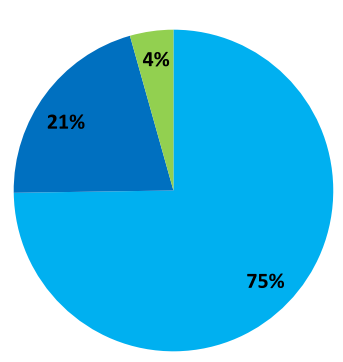

Fig. 2 Probability of observed temperature change in 2100 under alternate mitigation scenarios 


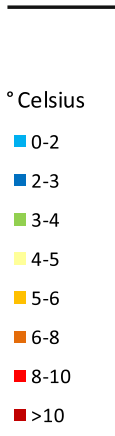

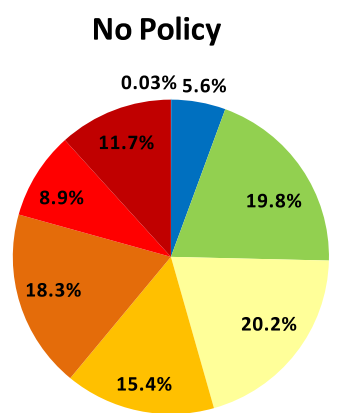

Developing Delay

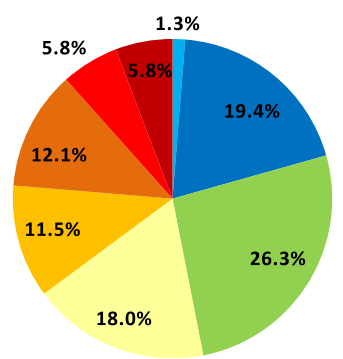

Full Participation

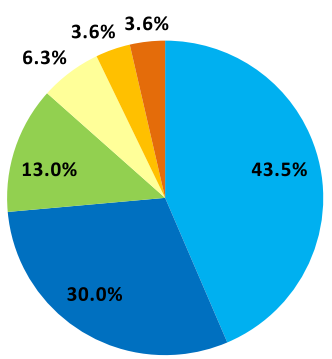

Fig. 3 Probability of long-term equilibrium temperature change assuming radiative forcing held constant at 2100 levels under alternate mitigation scenarios

change by as much as 500 years. Even when $\mathrm{CO}_{2}$ e concentrations are stabilized, observed temperatures would continue to rise for centuries before the equilibrium temperature changes are achieved.

A common practice for calculating the equilibrium temperature change when using a model that only runs through 2100 is to assume constant radiative forcing after 2100 (total radiative forcing in each scenario under different climate sensitivities are shown in Table 2). This may be a reasonable assumption in a policy case, where the additional post 2100 reductions needed to stabilize radiative forcing could reasonably be assumed to occur; however, in a no policy case it leads to overly optimistic results, since very large post 2100 reductions are being assumed in what is intended as a 'no policy' scenario. With these caveats, Fig. 3 depicts the probability of equilibrium temperature changes committed to in 2100 given the three scenarios described above, assuming constant radiative forcing in perpetuity for each scenario. Notably, the equilibrium temperature changes associated with the radiative forcings in 2100 are much larger than the observed temperature changes in 2100 . Under the no policy scenario there is nearly a $75 \%$ probability of equilibrium temperature change exceeding $4^{\circ} \mathrm{C}$, with a $21 \%$ chance of temperature change being greater than $8^{\circ} \mathrm{C}$.

As with the observed temperature changes, the probability of extreme equilibrium temperature changes are decreased, while the probability of smaller temperature

Fig. $4 \mathrm{CO}_{2}$ e concentrations through 2100 under alternate scenarios and climate sensitivities

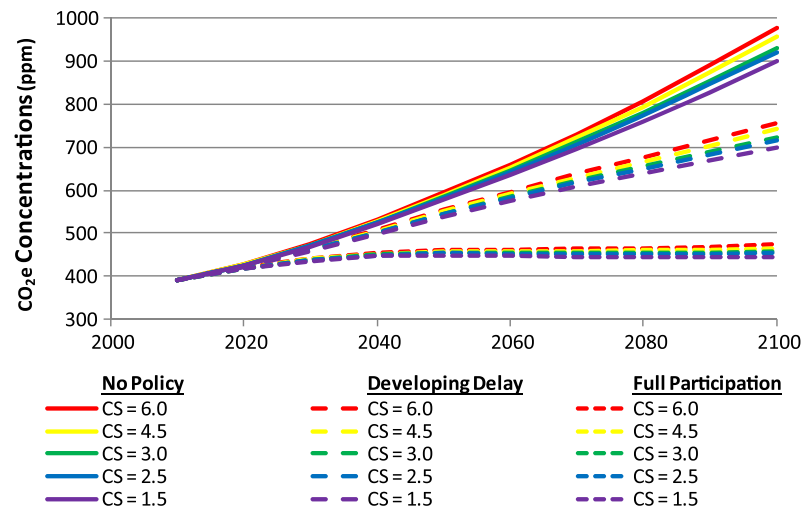


Table 2 Total radiative forcing $\left(\mathrm{W} / \mathrm{m}^{2}\right)$

\begin{tabular}{llllll}
\hline & \multicolumn{4}{l}{ RF in 2100 under alternate climate sensitivities } \\
\cline { 2 - 6 } & $\mathrm{CS}=1.5$ & $\mathrm{CS}=2.5$ & $\mathrm{CS}=3.0$ & $\mathrm{CS}=4.5$ & $\mathrm{CS}=6.0$ \\
\hline No policy & 6.3 & 6.4 & 6.5 & 6.6 & 6.7 \\
Developing delay & 4.9 & 5.1 & 5.1 & 5.3 & 5.4 \\
Full participation & 2.5 & 2.6 & 2.7 & 2.8 & 2.8 \\
\hline
\end{tabular}

changes is increased for both the full participation and developing economy delay scenarios. Under the no policy scenario the probability of staying below a $2{ }^{\circ} \mathrm{C}$ equilibrium temperature change is minute at only $0.03 \%$. Under the full participation scenario there is $44 \%$ chance of staying below $2^{\circ} \mathrm{C}$ and even under the delay scenario this probability is $1.3 \%$. The probability of staying between 2 and $3^{\circ} \mathrm{C}$ for equilibrium temperature change increases to $30 \%$ in the full global action scenario and $19 \%$ in the delay scenario from $5.6 \%$ in the no policy scenario, an increase of 24 and 13 percentage points, respectively.

We find that early action by the developed countries, even in the absence of mitigation efforts by developing economies prior to 2050, has a strong positive impact on the distribution over observed temperature outcomes in 2100 relative to the no policy case. There is a clear increase in the probability of achieving the G8 target of a temperature change of less than $2^{\circ} \mathrm{C}$ under the developing economy delay scenario, as compared to the no policy scenario. We also find that the delay scenario halves the probability of exceeding the most extreme temperature changes, greater than $10^{\circ} \mathrm{C}$, and reduces the probability of temperature changes greater than $6^{\circ} \mathrm{C}$ by 15 percentage points, from $38 \%$ to $23 \%$.

A key contribution of this work is the clear presentation of changes in temperature probability distributions over alternate scenarios, clearly demonstrating the large reductions in the risks of more extreme temperature change under mitigation scenarios, as compared with a no policy scenario. We show that these reductions in the risk of the worst outcomes are greatly reduced even under a scenario that models a delay in developing economy participation. While delay in mitigation efforts by developing economies is not an ideal outcome-the greatest changes are seen when the countries all begin mitigation efforts immediately-it is clear that the potential for this delay should no longer be used as a reason to prevent mitigation action in developed economies.

Acknowledgements The authors would like to gratefully acknowledge the helpful comments of two anonymous reviewers and several colleagues, especially Jae Edmonds, John Weyant and Katherine Calvin.

Open Access This article is distributed under the terms of the Creative Commons Attribution Noncommercial License which permits any noncommercial use, distribution, and reproduction in any medium, provided the original author(s) and source are credited.

\section{References}

Boden T, Marland G, Andres RJ (2010) National CO2 emissions from fossil-fuel burning, cement manufacture, and gas flaring: 1751-2007. Carbon Dioxide Information Analysis Center Oak Ridge National Laboratory. http://cdiac.ornl.gov/ftp/ndp030/nation1751_2007.ems. Accessed 28 February 2011 
Calvin KV, Edmonds J, Bond-Lamberty B, Clarke LE, Kim SH, Kyle P, Smith SJ, Thomson A, Wise $\mathrm{M}$ (2009) 2.6: limiting climate change to $450 \mathrm{ppm} \mathrm{CO}_{2}$ equivalent in the 21st century. Energy Econ 31(2):S107-S120. doi:10.1016/j.eneco.2009.06.006

Clarke LE, Edmonds J, Krey V, Richels RG, Rose S, Tavoni M (2009) International climate policy architectures: overview of the EMF 22 international scenarios. Energy Econ 31(2):S64-S81. doi:10.1016/j.eneco.2009.10.013

Driessen P (2009) Back to the "Good Old Days." www.globalwarming.org/2009/05/01/back-to-thegood-old-days/. Accessed 26 October 2010

RPC Energy Facts (2009) U.S. cap-and-trade without international action: all pain and no gain. http://rpc.senate.gov/public/files/EnergyFactsInternationalAction.pdf. Accessed 26 October 2010

Roe G, Baker M (2007) Why is climate sensitivity so unpredictable? Science 318:629-632. doi:10. $1126 /$ science. 1144735

United Nations (2009) Report of the conference of the parties on its fifteenth session, held in Copenhagen from 7 to 19 December 2009: Decision 2/CP.15: Copenhagen Accord. http://unfccc. int/resource/docs/2009/cop15/eng/11a01.pdf\#page=4. Accessed 15 February 2011

U.S. Energy Information Administration (2010) International energy outlook 2010. Washington, DC

U.S. Environmental Protection Agency (2010) EPA analysis of the American power act in the 111th congress. http://www.epa.gov/climatechange/economics/pdfs/EPA_APA_Analysis_6-1410.pdf. Accessed 25 October 2010

U.S. Government Interagency Working Group on Social Cost of Carbon (2010) Technical support document: social cost of carbon for regulatory impact analysis under Executive Order 12866. http://www.epa.gov/otaq/climate/regulations/scc-tsd.pdf. Accessed 28 October 2010

White House (2009) Fact Sheet: Meeting the Internatoal Clean Energy and Climate Change Challenges. http://www.whitehouse.gov/the-press-office/fact-sheet-meeting-international-cleanenergy-and-climate-change-challenges

Webster M, Forest C, Reilly J, Babiker M, Kicklighter D, Mayer M, Prinn, Sarofim M, Sokolov A, Stone P, Wang C (2003) Uncertainty analysis of climate change and policy response. Clim Change 61(3):295-320. doi:10.1023/B:CLIM.0000004564.09961.9f

Wigley T (2011) MAGICC v.5.3. http://www.cgd.ucar.edu/cas/wigley/magicc/. Accessed 3 March 2011

Weitzman M (2010) GHG targets as nsurance against catastrophic climate damages. http://www. economics.harvard.edu/faculty/weitzman/files/1A1A.InsuranceCatastrophicRisks.pdf 